\title{
High-temperature stability of yttria-stabilized zirconia thermal barrier coating on niobium alloy-C-103
}

\author{
S S PANWAR ${ }^{1,2, *}$, T UMASANKAR PATRO ${ }^{2}$, K BALASUBRAMANIAN ${ }^{2}$ and B VENKATARAMAN ${ }^{3}$ \\ ${ }^{1}$ Defence Research and Development Laboratory, Kanchanbagh, Hyderabad 500 058, Telangana, India \\ ${ }^{2}$ Department of Materials Engineering, Defence Institute of Advanced Technology (DU), Girinagar, \\ Pune 411 025, Maharashtra, India \\ ${ }^{3}$ Defence Metallurgical Research Laboratory, Kanchanbagh, Hyderabad 500 058, Telangana, India
}

MS received 5 September 2015; accepted 5 October 2015

\begin{abstract}
Thermal barrier coatings (TBCs) of yttria-stabilized zirconia (YSZ) of different thicknesses with an intermediate bond coat were deposited on $\mathrm{C}-103 \mathrm{Nb}$ alloy using the air plasma spraying technique. The coatings were subjected to rapid infra-red (IR) heating $\left(\sim 25^{\circ} \mathrm{C} \mathrm{s}^{-1}\right)$ up to $\sim 1250^{\circ} \mathrm{C}$ and exposed up to $100 \mathrm{~s}$ at this temperature with heat flux varying from 55 to $61 \mathrm{~W} \mathrm{~cm}^{-2}$. The TBCs were found to be stable and intact after the heat treatment. In contrast, at the same conditions, the uncoated C-103 alloy specimen showed extensive oxidation followed by weight loss due to spallation. A maximum temperature drop of $\sim 200^{\circ} \mathrm{C}$ was observed on the opposite side of the coated alloy with $600 \mu \mathrm{m}$ YSZ coat; as against negligible temperature drop in case of bare alloy specimen. The temperature drop was found to increase with the coating thickness of YSZ. The coatings before and after IR heating were investigated by scanning electron microscopy, X-ray diffraction, electron probe microanalysis, microhardness and residual stress measurements in order to understand the effect of thermal shock on the properties of the TBC. On account of these high-temperature properties, YSZ coating along with the bond coat is expected to find potential thermal barrier coating system on niobium alloys for supersonic vehicles.
\end{abstract}

Keywords. Thermal barrier coating; yttria-stabilized zirconia; plasma spraying; thermal conductivity; oxidation resistance.

\section{Introduction}

Thermal barrier coatings (TBCs) are applied largely on hightemperature components of gas turbine and internal combustion engines in order to protect metal components from oxidation and creep, which remarkably reduce the component's durability and efficiency [1-3]. TBCs have been reported to decrease the underlying metal temperature up to $150^{\circ} \mathrm{C}$ and retain thermal, mechanical and chemical properties of base metal [4-6]. A typical TBC system consists of an oxide ceramic top coat over a metallic bond coat. TBC should have a high thermal expansion coefficient, low thermal conductivity and good chemical and structural stability to withstand extreme service conditions. However, most of the oxides have low thermal expansion coefficient (TEC); hence a bond coat is applied on metal substrate prior to the oxide ceramic coating. The bond coat is generally an alloy of MCrAlY (where $\mathrm{M}$ is either Co and/or Ni), which has a TEC in-between that of metal substrate and ceramic top coat [7-9]. Therefore, the bond coat provides a suitable thermal expansion gradient to the substrate and the ceramic top coat [8]. The bond coat also provides a reasonable surface roughness for better mechanical interlocking with the ceramic coat

*Author for correspondence (panwardiat40@gmail.com)
[10,11]. Further, the ceramic top coat alone, although provides thermal insulation; but cannot prevent the atmospheric oxygen to diffuse through the pores present thereby and interact with substrate at elevated temperatures, which results in oxidation of metal substrate. The bond coat protects the substrate from such oxidation by interacting with diffused oxygen through the top coat at high temperatures. This causes formation of oxide scale, which is termed as thermally grown oxide (TGO). Although, the TGO protects the substrate from oxidation; but, excess growth of it leads to failure of the TBC system. Moreover, oxidation of $\mathrm{Al}$ present in the intermediate bond coat (MCrAlY) was found to be the primary degradation mechanism of TBC failure [7-9,12-14].

Yittria-stabilized zirconia (YSZ) coatings along with metallic bond coats; such as CoCrAlY, CoNiCrAlY have been extensively used as TBCs on various metallic substrates $[7,8,14]$. However, such a TBC system has not been applied on $\mathrm{Nb}$-based alloy. Further, most of the studies focused on functionally gradient TBCs [8,9,14-18]. Although such kind of TBC is beneficial for the component life; but may make the process tedious and time consuming. Traditionally, silicide coatings have been used on $\mathrm{Nb}$ alloys for scramjet combustor and vehicle acreage applications [19-21]. However, silicide coatings are generally used for oxidation protection; but not as TBC due to their higher thermal conductivity compared with YSZ [21]. 
In supersonic and hypersonic aircraft components, the heat flux is an order of magnitude higher than that of a gas turbine or an internal combustion engine. For such kind of applications, high heat flux is required for short time duration. Since, $\mathrm{Nb}$ alloys are being used for these applications, TBC with a prior bond coat is essential for better performance of components made by these alloys. Further, $\mathrm{Nb}$ alloys suffer from high temperature oxidation above $600^{\circ} \mathrm{C}$ [22]; although the melting temperature of these alloys is $\sim 2350^{\circ} \mathrm{C}$ [23]. Therefore, TBCs are used to provide thermal insulation as well as oxidation protection for these alloy systems to sustain thermal shock and extreme service conditions.

In the present work, YSZ as TBC with a prior bond coat of $\mathrm{NiCrAlY}$ is deposited on Nb base alloy, C-103 by air plasma spraying. High-temperature stability of the TBC coating was studied by rapid heating of the coating to $1250^{\circ} \mathrm{C}$. Hightemperature oxidation and thermal conductivity of the coatings along with the substrate were investigated. As-deposited YSZ coatings and coatings after heat treatment were characterized using X-ray diffraction (XRD) and scanning electron microscopy (SEM). Residual stress analysis (RSA) was carried out on the surface of the coated samples before and after heat treatment. The thermal conductivity was estimated using heat flux and temperature drop across test specimen during rapid IR heating.

\section{Experimental}

\subsection{Substrate and coating material}

A 3-mm-thick rolled sheet of niobium-based alloy, C-103 (Nb-10 Hf-1Ti) was used as substrate. The test coupons of size $50 \mathrm{~mm} \times 50 \mathrm{~mm}$ were cut from the sheets by wire cutting. The specimens were then cleaned by grit blasting using 40 mesh $\mathrm{Al}_{2} \mathrm{O}_{3}$ with inlet pressure of $3 \mathrm{kgf} \mathrm{cm}^{-2}$. Surface roughness of the specimens was found to be $\mathrm{Ra} \sim 3-4$. The specimens were cleaned using ultrasonication in acetone in order to degrease.

Prior to the deposition of TBC coating, NiCrAlY (AMPERIT, particle size 22-45 $\mu \mathrm{m}$ ) bond coat of thickness

Table 1. Air plasma spraying conditions adopted for the deposition of TBC system.

\begin{tabular}{|c|c|c|}
\hline Coating deposition parameters & Bond coat & Top coat \\
\hline Gun & F4MB & F4MB \\
\hline Argon flow (NLPM) & 44 & 43 \\
\hline $\mathrm{H}_{2}$ flow (NLPM) & 10 & 9.5 \\
\hline Current, amp (A) & 590 & 550 \\
\hline Carrier gas (NLPM) & 32 & 32 \\
\hline Voltage (V) & 75 & 70 \\
\hline Nozzle size $(\mathrm{mm})$ & 6 & 6 \\
\hline Distance $(\mathrm{mm})$ & 120 & 120 \\
\hline Feed rate $\left(\mathrm{g} \mathrm{min}^{-1}\right)$ & 35 & 35 \\
\hline Injector diameter (mm) & 1.5 & 1.8 \\
\hline Injector distance (mm) & 6 & 6 \\
\hline
\end{tabular}

$\sim 100 \mu \mathrm{m}$ was applied on the alloy surface. YSZ with a composition of $93 \% \mathrm{ZrO}_{2}-7 \% \quad \mathrm{Y}_{2} \mathrm{O}_{3}$ (AMPERIT, particle size $10-45 \mu \mathrm{m})$ was deposited using air plasma spraying at $100 \mathrm{kV}$ (Miller). Two different thicknesses, i.e., 300 and $\sim 600 \mu \mathrm{m}$ of YSZ coating were studied in order to understand the effect of YSZ coating thickness on TBC performance. The spraying conditions adopted for deposition are given in table 1 .

\subsection{Rapid IR heating test}

The rapid heating test was performed using a $150 \mathrm{~kW}$ electric infrared (IR) heater of size $300 \mathrm{~mm} \times 300 \mathrm{~mm}$. The uncoated and coated test samples were mounted vertically adjacent to each other facing towards the IR heater as shown in figure 1 . In case of TBC-coated samples, the coating side was faced towards the heater. The bare and the alloy with TBC were placed at A and B positions, respectively, as shown in figure 1. The bare alloy was used as reference with respect to which the temperature difference was measured. The distance between the samples and the heater was kept $\sim 75 \mathrm{~mm}$. The heat flux gauge was mounted between the two test specimens (bare and coated) (figure 1). R-type thermocouples were used to measure the surface temperature of test specimens with respect to time. In uncoated specimen, two thermocouples were welded at the two ends on the front surface (R1 and R2) (facing towards the heater) and two more (R3 and R4) were welded on the back surface. The thermocouples welded on the back surface acted as controller and redundant thermocouples, respectively. In coated specimen, only two thermocouples (R5 and R6) were welded in the back side (figure 1). The thermal barrier efficiency of coating material was measured in terms of the temperature difference observed at the back surface of coated specimen with respect to that of the uncoated specimen. All test specimens were coated with Zynolyte black paint (emissivity 0.94) to ensure maximum heat absorption by the surfaces facing towards the IR heater.

The oxidation studies of test specimens were carried out at $1250^{\circ} \mathrm{C}$ by heating the specimens rapidly at $\sim 25^{\circ} \mathrm{C} \mathrm{s}^{-1}$ using IR heater in atmospheric conditions. The IR heater was programmed in such a way that the test temperature was reached within $45 \mathrm{~s}$ and the test coupons were kept at this temperature for various time periods, i.e., 30 and 100 s. For this, two sets of experiments were conducted. The overall weight change of test specimens were measured before and after exposure to IR heating using digital physical balance (Sartorius).

\subsection{Estimation of thermal conductivity}

The thermal conductivity was estimated using the heat flux and the temperature drop across the test specimen data. The temperature on the front wall, back wall and heat flux with the increase in temperature were recorded as a function of time and the thermal conductivities of bare substrate and coated specimen are estimated using the following 


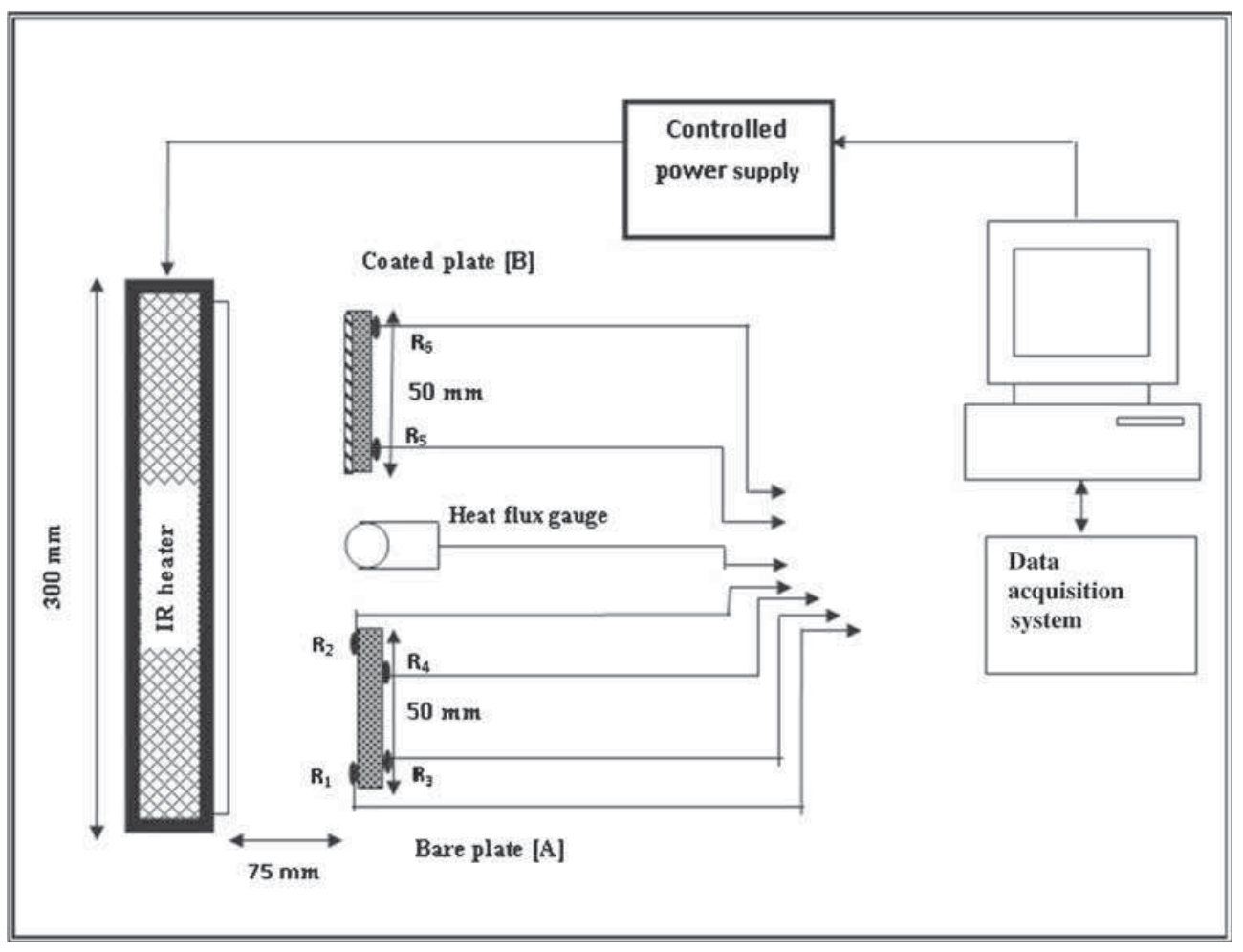

Figure 1. Schematic representation of the experimental set-up for rapid IR heating.

relationship as given in equation (1). Heat losses due to convection and radiation are assumed to be negligible

$$
K=\frac{Q}{t} \times \frac{L}{A \times \Delta T},
$$

where $K$ is the thermal conductivity, $Q$ the heat flux, $t$ the time, $L$ the thickness, $A$ the area and $\Delta T$ the temperature difference. Rule of mixture was applied to determine the thermal conductivity of TBC (YSZ along with bond coat) coating is as given below

$$
1 / K_{\mathrm{cm}}=1 / K_{\mathrm{b}}+1 / K_{\mathrm{c}},
$$

where $K_{\mathrm{cm}}, K_{\mathrm{b}}$ and $K_{\mathrm{c}}$ are the thermal conductivity values of coated substrate, bare alloy and TBC (YSZ+bond coat), respectively. Three specimens were tested for each coating thickness and the average values of thermal conductivities are reported.

\subsection{Structural and mechanical characterization}

The cross-section and microstructure of as-prepared coating and after IR heating were investigated using SEM (Quanta 450, FEI, USA). The phase changes were ascertained by XRD (PW1830, Philips) using $\mathrm{Cu} \mathrm{K}_{\alpha}$ radiation with $\lambda=$ $0.154 \mathrm{~nm}$. The specimens were sectioned using ISOMET diamond cutter (Buehler). The sectioned samples were initially polished using emery papers in increase grit size (800 2500), and subsequently lapping carried out with 3 and $1 \mu \mathrm{m}$ diamond paste. The elemental composition on the surface was investigated using electron probe micro-analysis (EPMA) (CAMICA-SX100). Hardness along the cross-section of the coating was measured using digital micro-hardness tester (MMT-X3, Matsuzawa).

Residual stresses on the coating surface before and after exposure of high temperature $\left(\sim 1250^{\circ} \mathrm{C}\right)$ were measured using a portable X-ray residual stress analyzer (iXRD) (Proto). The changes in the interplanar spacing were monitored using the Bragg scattering angle to detect the elastic strain. Stress was evaluated from strain using Young's modulus and Poisson's ratio by taking elastic anisotropy of the material into consideration. The experimental details for these measurements are as follows: YSZ $(\mathrm{Cr}-\mathrm{K} \alpha)$ (BCC-hkl-331), Bragg's angle = $153^{\circ}$ and wavelength $=2.29 \AA$. The measurements were carried out at five different locations on $20 \times 20 \mathrm{~mm}^{2}$ specimen surface: four points along the diagonal and fifth at centre of the test specimen.

\section{Results and discussion}

\subsection{Thermal barrier performance}

The pre-set temperature for IR heating was $1250^{\circ} \mathrm{C}$. The temperature profile as a function of time is shown in figure 2 . The temperature showed a sharp increase and attained $1250^{\circ} \mathrm{C}$ within $45 \mathrm{~s}$ and was almost invariant thereafter. The small hump in case of bare alloy in figure 2 around the maximum temperature may be due to heat loss. The heat flux 


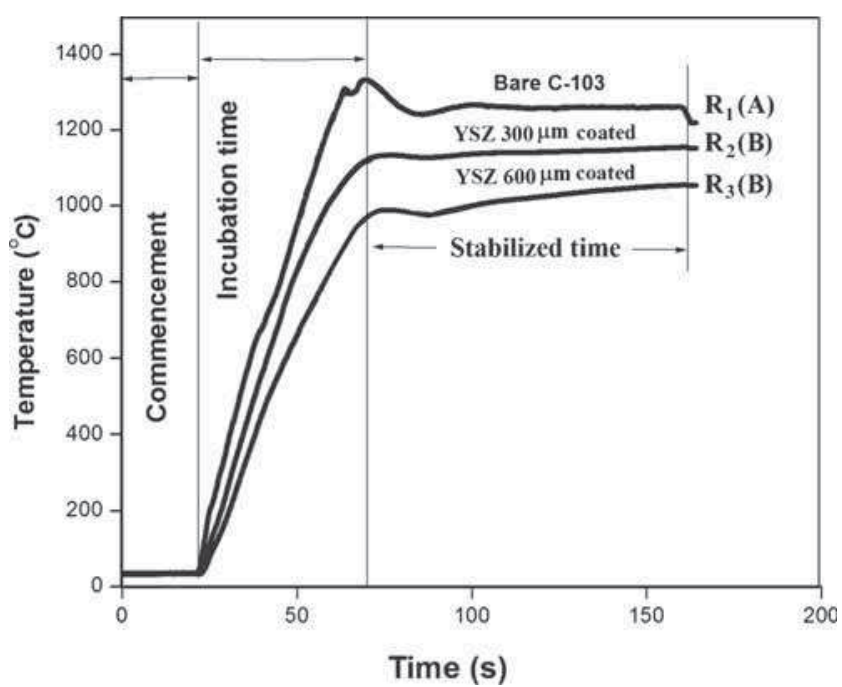

Figure 2. Temperature of back-wall as a function of time of bare alloy and the alloy with TBC where the YSZ coating was 300 and $600 \mu \mathrm{m}$ on top of a $\sim 100 \mu \mathrm{m}$ NiCrAlY bond coat.

was found to vary between 55 and $61 \mathrm{~W} \mathrm{~cm}^{-2}$ during the tests for various specimens. Initially, a test was conducted by placing the bare $\mathrm{C}-103$ at both $\mathrm{A}$ and $\mathrm{B}$ positions (figure 1). As expected, the temperature drop was found to be negligible for the bare C-103 alloy. Then, the tests were conducted by placing the bare C-103 and YSZ-coated C-103 at $\mathrm{A}$ and $\mathrm{B}$ positions, respectively. For all the experiments performed with bare $\mathrm{C}-103$ alloy, the back-wall temperature was reached to a maximum of $1250^{\circ} \mathrm{C}$ with a linear increase in temperature within $45 \mathrm{~s}$ as shown in figure 2 . However, the corresponding back-wall temperatures for the YSZ-coated C-103 were found to be significantly lower as compared to that of bare alloy. Further the temperature drop was found to increase with the coating thickness. The maximum temperatures attained for 300 and $600 \mu \mathrm{m}$ YSZ-coated alloys were $\sim 1175$ and $\sim 1050^{\circ} \mathrm{C}$, respectively (figure 2 ). The thickness of bond coat was same in both the cases. The temperature drop for bare and coated specimens is presented in figure 3 . For bare alloy, the temperature drop was found to be only $4-10^{\circ} \mathrm{C}$; whereas for the coated ones the values were $\sim 75$ and $\sim 200^{\circ} \mathrm{C}$ for specimens with 300 and $600 \mu \mathrm{m}$ YSZ coatings, respectively. The higher temperature drop in case of thicker coating is likely due to its higher insulation effect. However, the time taken to achieve the maximum temperature remained almost same $(\sim 45 \mathrm{~s})$ in all the cases (figure 2 ). The significant temperature drops are essentially due to the presence of YSZ coating and its lower thermal conductivity compared with the base metal. The thermal conductivity values of C-103 alloy, YSZ and NiCoAlY bond coat are 41.4, 1.1 and $16.1 \mathrm{~W} \mathrm{~m}^{-1} \mathrm{~K}^{-1}$, respectively [14]. The lower thermal conductivities of bond coat and YSZ than that of C-103 are responsible for relatively slow rise in temperature during incubation time at the back-wall surface of the coated C-103 alloy and result in higher temperature drop (figure 2).

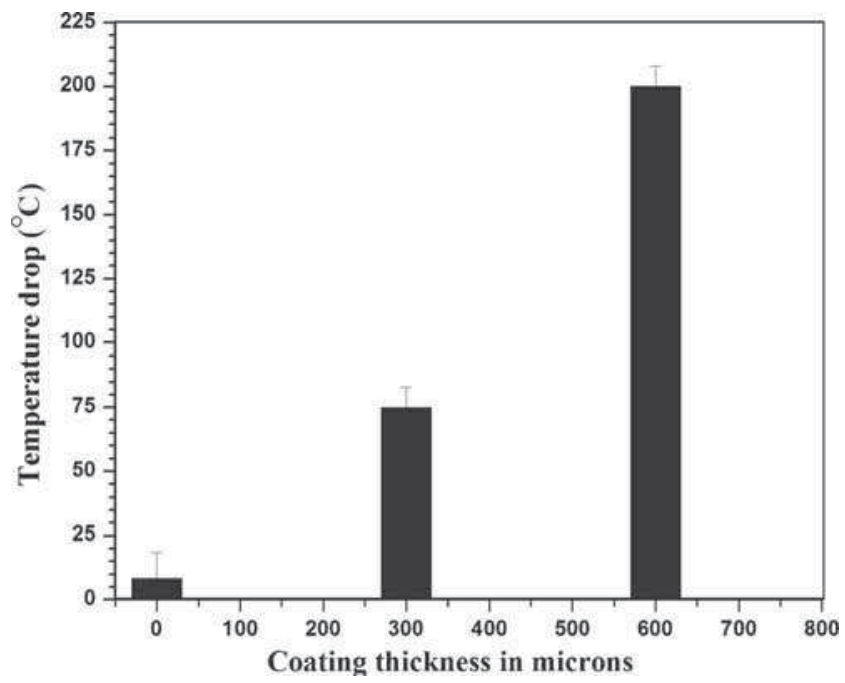

Figure 3. Temperature drop vs. YSZ coating thickness. The samples were exposed to $1250^{\circ} \mathrm{C}$ for $100 \mathrm{~s}$. The YSZ-coated samples were also coated with $\sim 100 \mu \mathrm{m} \mathrm{NiCrAlY}$ bond coat in prior.

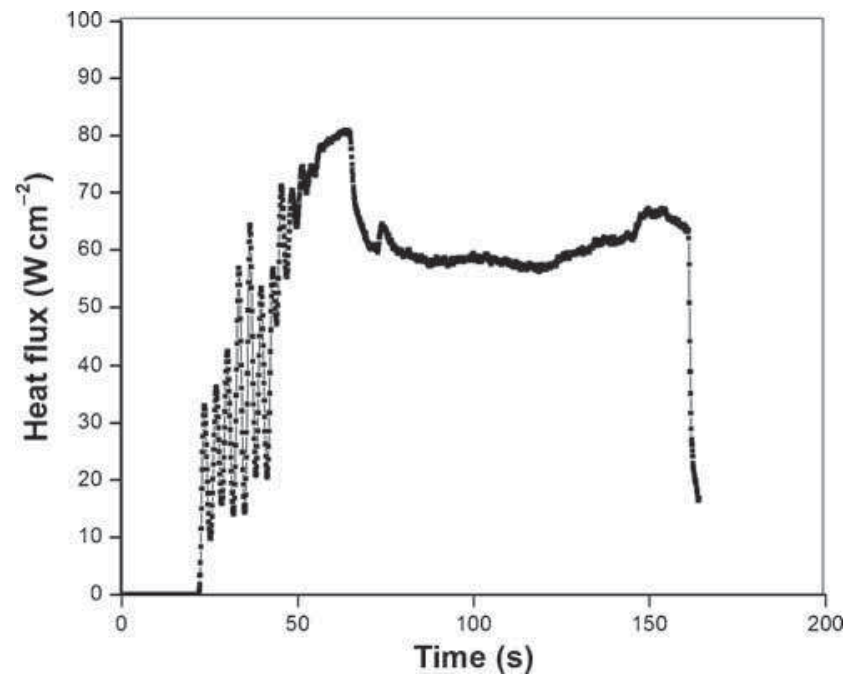

Figure 4. Heat flux as a function of time during IR rapid heating test.

The heat flux as a function of time is shown in figure 4 . The heat flux increased with time till $45 \mathrm{~s}$ then showed a decrease and became almost independent of time for rest of the experiment. The heat flux at which it showed a plateau is $\sim 60 \mathrm{~W} \mathrm{~cm}^{-2}$ (figure 4). Thermal conductivity of TBC (bond coat and YSZ coating), determined by rule of mixture and the thermal conductivities of bare and coated alloys, measured using heat flux and temperature drop as a function of temperature are elucidated in figure $5 \mathrm{a}$. The thermal conductivity was found to increase with the increase in temperature for the bare alloy; whereas the TBC and the coated alloy did not show a significant change in thermal conductivity with temperature. The thermal conductivity of substrate at $1250^{\circ} \mathrm{C}$ was found to be $\sim 44 \mathrm{~W} \mathrm{~m}^{-1} \mathrm{~K}^{-1}$, which closely matches with the literature $\left(42.4\right.$ and $44.7 \mathrm{~W} \mathrm{~m}^{-1} \mathrm{~K}^{-1}$ at 1200 and 


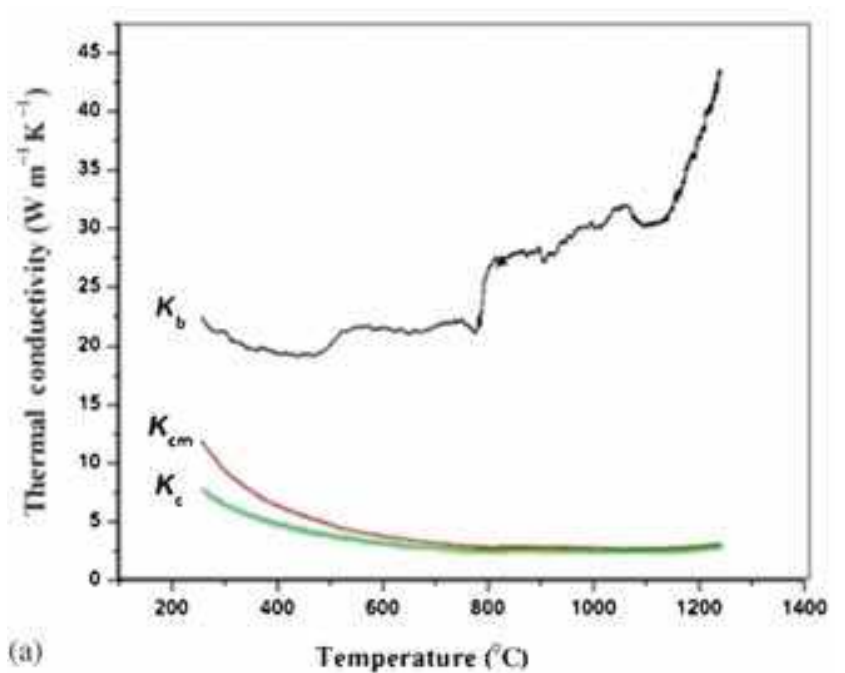

(a)

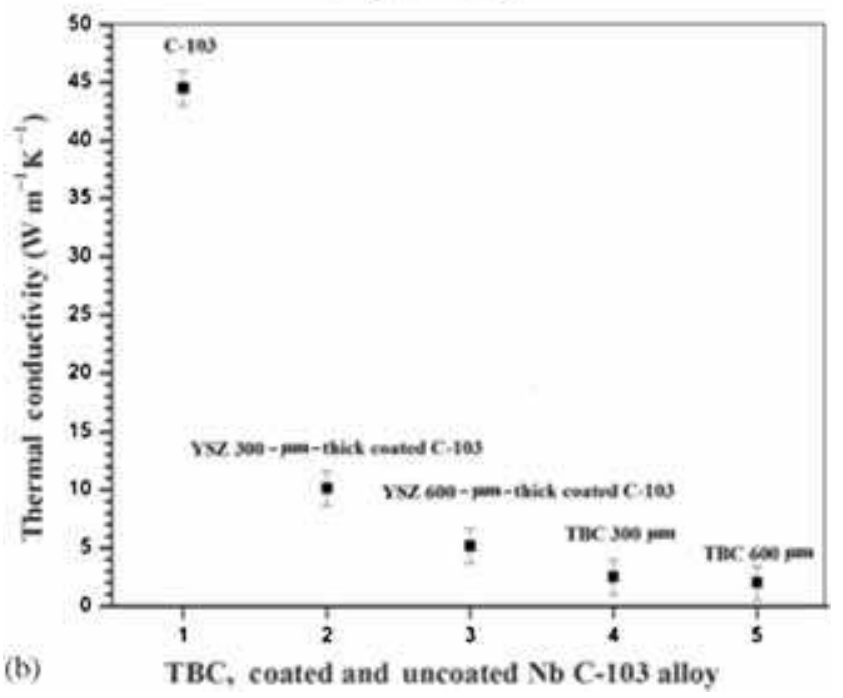

Figure 5. Thermal conductivity of $\operatorname{TBC}\left(K_{\mathrm{c}}\right)$, bare alloy $\left(K_{\mathrm{b}}\right)$ and TBC-coated alloy $\left(K_{\mathrm{cm}}\right)$ with $600 \mu \mathrm{m}$ YSZ coating (a) as a function of temperature and (b) thermal conductivity values for various samples at $1250^{\circ} \mathrm{C}$. The thermal conductivity values for only TBCs (TBC 300 and $600 \mu \mathrm{m}$ ) are obtained by rule of mixture.

$1305^{\circ} \mathrm{C}$, respectively) [23]. The thermal conductivity values for the TBC coatings of thicknesses 300 and $600 \mu \mathrm{m}$ are $\sim 2.5$ and $\sim 2.0 \mathrm{~W} \mathrm{~m}^{-1} \mathrm{~K}^{-1}$, respectively, at $1250^{\circ} \mathrm{C}$. However, the thermal conductivity values for the coated substrates with YSZ coating of 300 and $600 \mu \mathrm{m}$ are found to be $\sim 10$ and $\sim 5.0 \mathrm{~W} \mathrm{~m}^{-1} \mathrm{~K}^{-1}$ at $1250^{\circ} \mathrm{C}$, respectively. The average values of thermal conductivities of uncoated, coated $\mathrm{Nb} \mathrm{C}$ 103 alloy and TBC coating are presented in figure $5 \mathrm{~b}$. The values showed significant decreases in the alloys with TBC.

\subsection{Oxidation resistance studies}

During the IR heating experiments, the bare substrate was found to undergo a severe oxidation followed by spallation, as shown in figure 6. It is important to mention that the spallation of oxide debris occurred spontaneously without any mechanical action after $30 \mathrm{~s}$ (after reaching maximum temperature) of IR heating in the bare alloy. The spallation was found to increase with the IR heating time in case of bare alloy. Interestingly, such spallation of surface layer was not observed in YSZ-coated specimen; except marginal mass loss observed because of the spallation on the back-wall surface, where there was no coating. The mass loss in uncoated specimen due to spallation of oxide layer at different time periods is presented in figure 7. It was observed that the mass loss of the bare substrate increased progressively with time. The total mass loss for bare and coated specimens without any mechanical action after $100 \mathrm{~s}$ exposure to $1250^{\circ} \mathrm{C}$ is also shown in figure 7. As seen in the figure, the YSZ-coated alloy exhibited significantly lower mass loss compared to the uncoated specimen after $100 \mathrm{~s}$ of exposure, which indicates a higher thermal stability of YSZ-coated alloy than that of bare alloy. This further indicates the strong adhesion between the YSZ coat and the alloy substrate. Mass loss is marginally higher in case of $600 \mu \mathrm{m}$ coating than $300 \mu \mathrm{m}$ coating (figure 7). This may be attributed to the higher surface roughness of $600 \mu \mathrm{m}$ coating $(\mathrm{Ra} \sim 4.8)$ as compared to that of $300 \mu \mathrm{m}(\mathrm{Ra} \sim 2.6)$. The integration of the TBC layer to the alloy substrate even after rapid heating to $1250^{\circ} \mathrm{C}$ suggests that the C-103 alloy with the present coating system (YSZ coat with NiCrAlY bond coat) could be a potential candidate for aerospace applications.

\subsection{Microhardness properties}

The microhardness values across the cross-section of YSZcoated substrate before and after exposure to $1250^{\circ} \mathrm{C}$ for $100 \mathrm{~s}$ in atmospheric conditions are plotted in figure 8 . Figure $8 \mathrm{a}$ and $b$ presents the hardness along the cross-section of the coatings of 300 and $600 \mu \mathrm{m}$ thick on the substrates, respectively. As expected, the ceramic coating is harder than both the bond coat and C-103 alloy. From the hardness values, it is evident that upon exposure to elevated temperatures, the surface hardness of the YSZ coating further increased. This may be due to the combined effect of densification of the coating during IR heating and the phase change occurred in YSZ as inferred by XRD and discussed later. However, the hardness of the underneath bond coat and substrate layers remained unaffected.

\subsection{Microstructure and residual stress analysis}

In order to study the effect of IR heating on the stability of the YSZ coating, cross-sectional microstructure was studied by SEM. Figure 9 presents the SEM images of YSZ coating of 300 and 600- $\mu \mathrm{m}$-thick as-deposited (figure 9a and b) and after IR heating for $30 \mathrm{~s}$ (figure 9c and d) and $100 \mathrm{~s}$ (figure 9e and $\mathrm{f}$ ). As seen in the images, the thickness of the YSZ coating is reasonably uniform with a variation of about 40-50 $\mu \mathrm{m}$. Moreover, the TBC was deposited on a relatively rough surface $(\mathrm{Ra} \sim 3-4)$ in order to increase the mechanical interlocking with the substrate and to achieve enhanced interfacial 


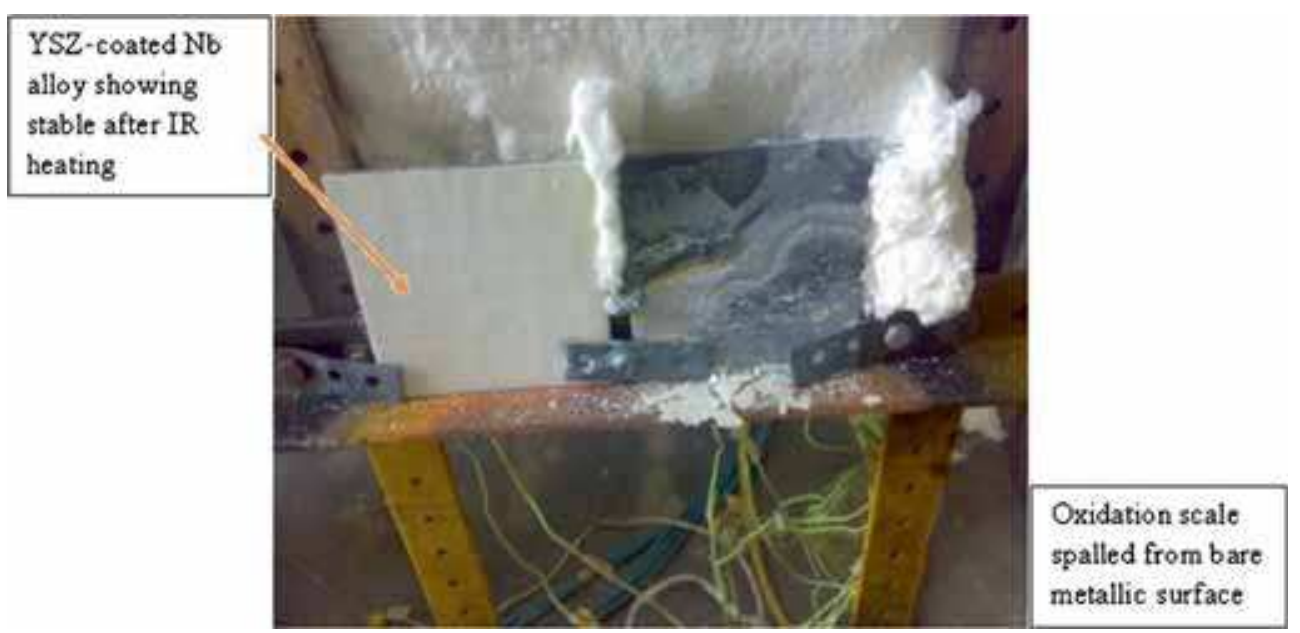

Figure 6. YSZ coated $(600 \mu \mathrm{m})$ (left) and uncoated (right) specimens after exposure to $1250^{\circ} \mathrm{C}$ for $30 \mathrm{~s}$ in atmospheric conditions.

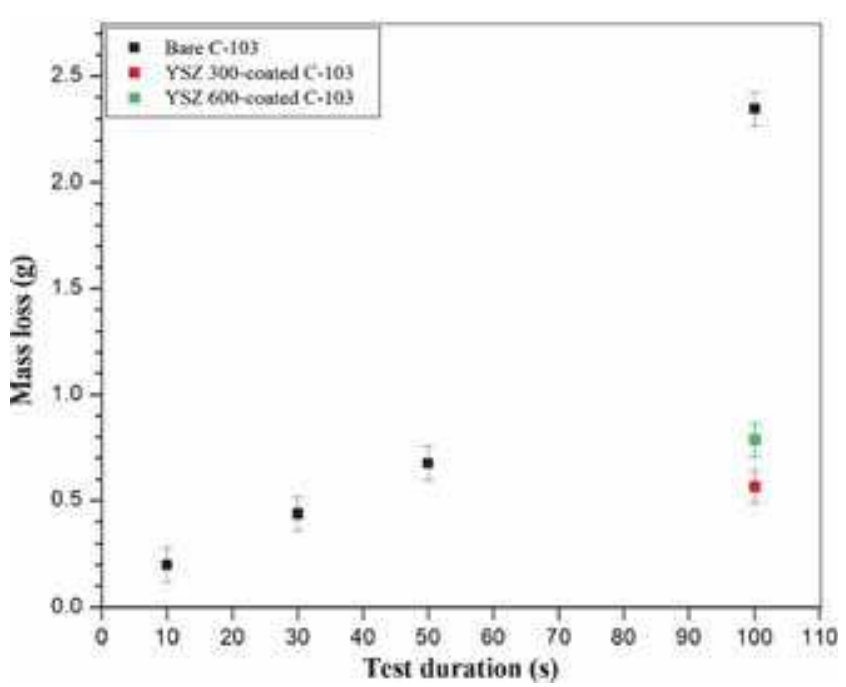

Figure 7. Mass loss as a function of time for uncoated and YSZcoated alloys exposed to $1250^{\circ} \mathrm{C}$ in atmospheric condition.

bond strength. Further, the distinct boundary between porous ceramic top coat and dense metallic bond coat can clearly be seen in these images (figure 9). Several horizontal (along the coating thickness) and vertical (normal to the coating thickness) cracks can be noticed in the cross-section after IR heating and the number of cracks increased with IR heating time (figure $9 \mathrm{c}-\mathrm{f}$ ). These cracks are most likely generated due to thermal shock owing to rapid IR heating and thermal mismatch between the underlying bond coat and the YSZ coating; notwithstanding the bond coat mitigates the thermal mismatch between the metal substrate and YSZ coat to an extent. Horizontal cracks cause debonding of coating, hence undesirable. However, vertical cracks in optimum numbers are helpful in relieving the surface stresses $[3,15]$. It was found that the size and number of vertical cracks increased with coating thickness (figure $9 \mathrm{~d}$ and f). This is likely due to lower thermal conductivity, better mechanical interlocking at the
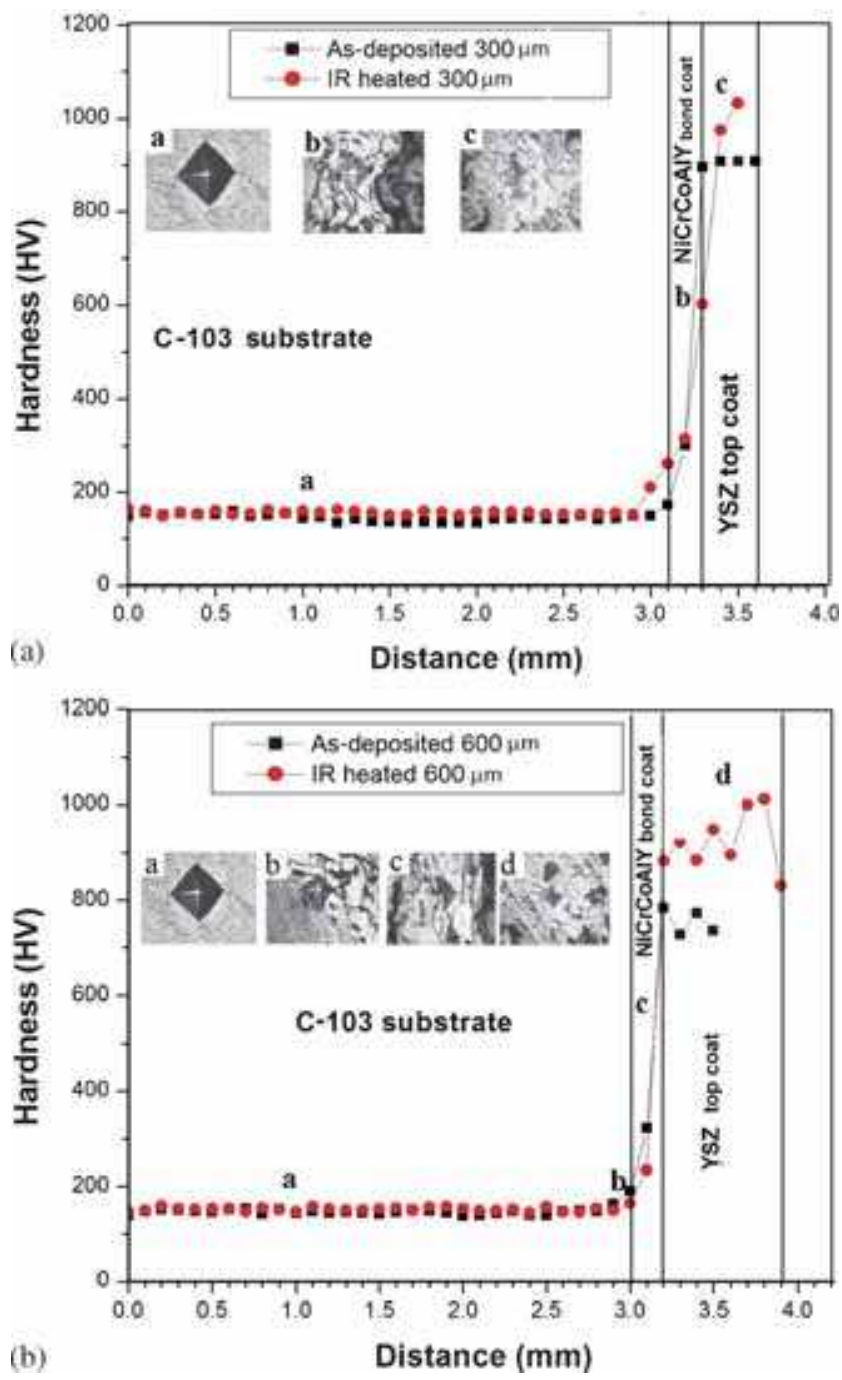

Figure 8. Microhardness across the cross-section of alloy substrate and TBC with YSZ coating of (a) $300 \mu \mathrm{m}$ thick and (b) 600 $\mu \mathrm{m}$ thick before and after IR heating. The indentation impressions are shown in the inset. 

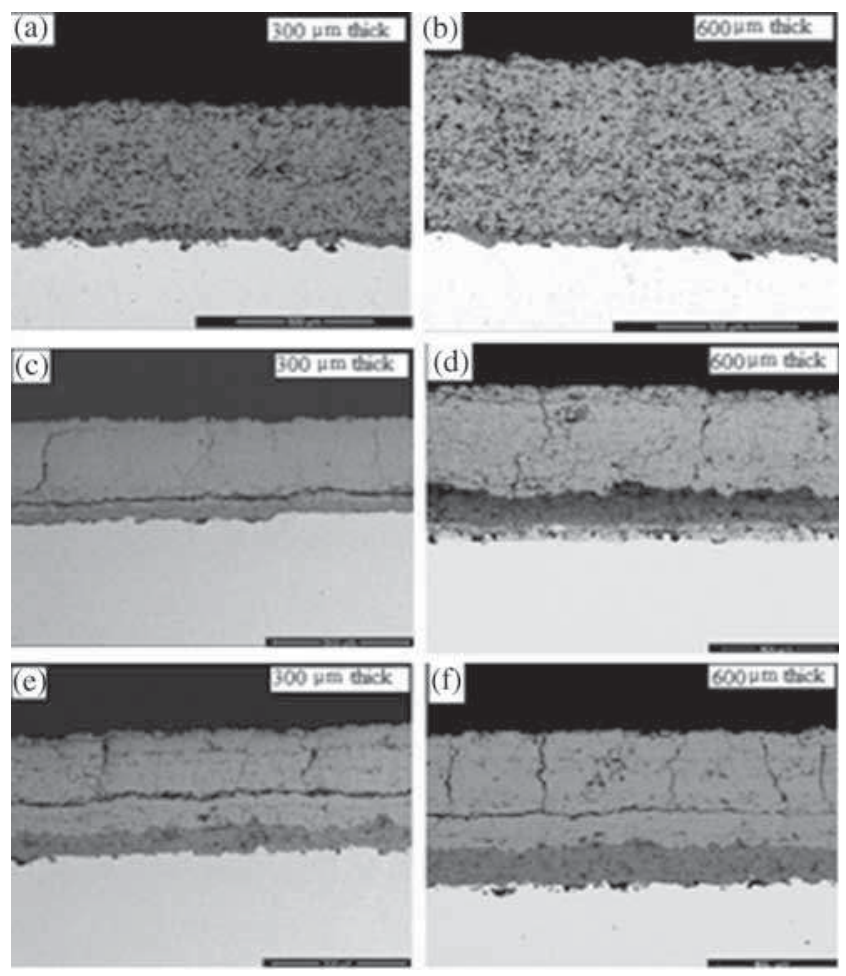

Figure 9. SEM micrographs of YSZ coating (a and $\mathbf{b}$ ) as deposited, (c and d) exposed to $1250^{\circ} \mathrm{C}$ for $30 \mathrm{~s}$ and (e and f) for $100 \mathrm{~s}$.

interface and higher stress relieving ability of thicker coating. The SEM images further reveal that more uniform and thinner bond coat leads to horizontal cracks close to the interface; whereas, non-uniform and thicker bond coat leads to stronger interface with ceramic top coat which might prevent formation of horizontal cracks close to the bond coat (figure 9). The strong interface along with few vertical micro-cracks in ceramic coating was likely responsible for enhancement of thermal shock resistance, which is supported by the adherence of TBC layer to the substrate even after rapid heating to high temperature.

Owing to the large differences in elastic modulus, coefficient of thermal expansion, and hardness between the bond coat and YSZ coating layers, thermal and mechanical stresses are generated at the interface of two layers or sometimes within the coating itself during deposition. Maximum principal and shear stresses with standard deviation on the coating surface before and after IR heating are presented in figure 10. It can be seen that the surface residual stresses decreased in both the coating thicknesses (300 and $600 \mu \mathrm{m})$ after rapid IR heating, which indicates the stress relaxation on the surface. However, the principal stresses decreased to an higher extent compared with the shear stresses. Notably, the average normal stress decreased from $\sim 73 \mathrm{MPa}$ for asdeposited $600 \mu \mathrm{m}$ coating to $\sim 47 \mathrm{MPa}$ for the same coating after IR heating. Further, the decrease in stresses as a result of IR heating is more in thicker coating. This indicates that the stress relaxation is more pronounced in thicker coating, which agrees with the earlier report [24]. The stress relaxation is likely due to formation of cracks on the coating surface as shown in figure $9 \mathrm{c}-\mathrm{f}$. Higher residual stresses require formation of higher number of micro-cracks on the surface in order to unlock the stresses. This phenomenon could also be confirmed by the fact that higher number of micro-cracks were seen in $600 \mu \mathrm{m}$ coating in comparison to $300 \mu \mathrm{m}$ coating (figure 9c-f). Further, more number of vertical cracks and networks of non-directional micro-craks were observed near the interface and the top coat in case of thicker coating (figure 9).

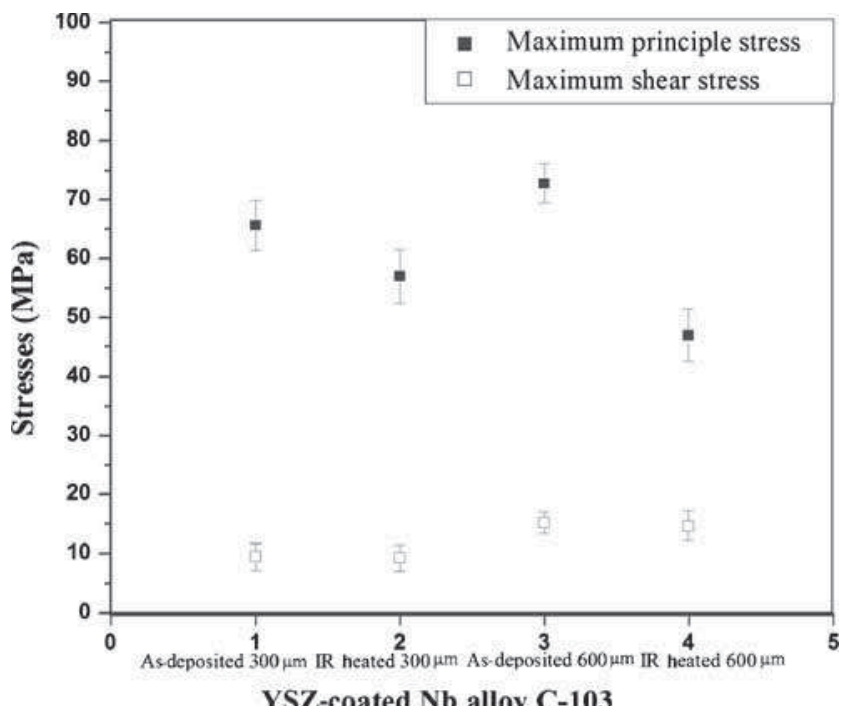

Figure 10. Maximum principle and shear stresses on YSZ coating surface before and after IR heating for $100 \mathrm{~s}$.

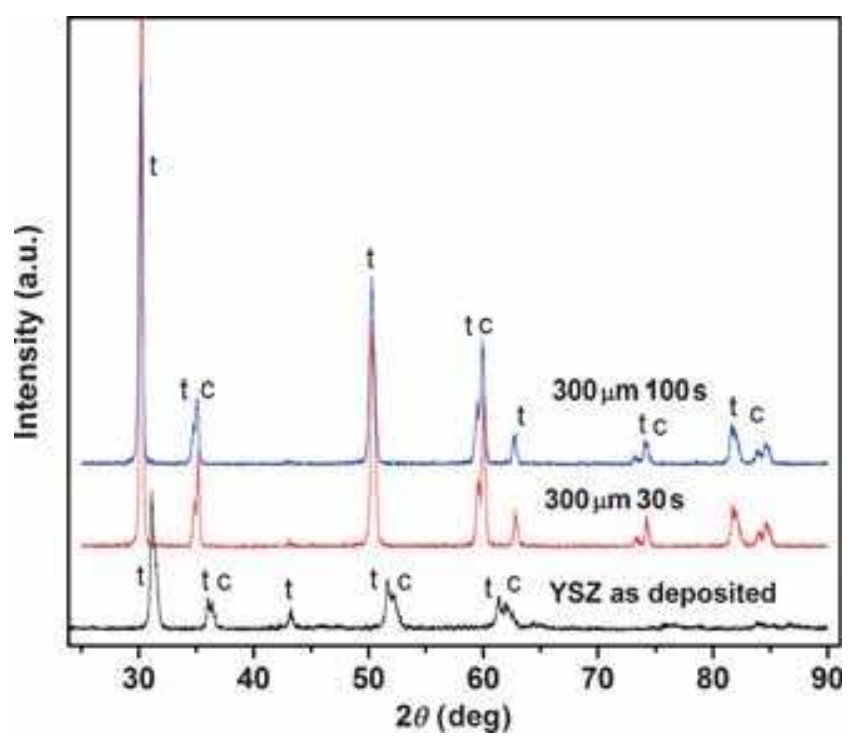

Figure 11. XRD patterns of YSZ coating of 300- $\mu \mathrm{m}$-thick asdeposited and after IR heating for 30 and 100s, $t$ and $c$ are denoted for tetragonal and cubic phases, respectively. 


\subsection{Strain relaxation by XRD}

XRD patterns of the as sprayed $(300 \mu \mathrm{m})$ and IR heated for different time periods are presented in figure 11. The presence of tetragonal and cubic phases of $\mathrm{ZrO}_{2}$ is evident by the presence of all the peaks of YSZ. Further, transformation of tetragonal to cubic phase is likely to undergo by the simultaneous diminishing of the peak at $2 \theta \sim 45^{\circ}$ and appearance of a new peak at $2 \theta \sim 75^{\circ}$ as a result of heat treatment. It is also observed that several peaks were shifted to lower $2 \theta$ values or higher $d$-spacings upon heat treatment. This indicates development of homogeneous strain in the YSZ coating. For instance, the most intense peak at $2 \theta \sim 31.1^{\circ}$ with a corresponding $d$-spacing of $\sim 2.87 \AA$ in as coated YSZ specimen showed a significant shift in $2 \theta$ to $\sim 30.3^{\circ}$ ( $d$-spacing $\sim 2.95 \AA$ ) after IR heating for both 30 and $100 \mathrm{~s}$. From the $d$ spacings, a negative strain of $\sim 3 \%$ is estimated on the coating after heat treatment. This indicates the strain relaxation in the coating after IR heating, which is supported by the residual stress relaxation studies as discussed earlier.

\subsection{EPMA studies}

The intermediate NiCrAlY bond coat prevents oxidation of alloy substrate at high temperature and enhances adhesion of top coat with the substrate. During IR heating, the elements present in the bond coat oxidize and form a TGO scale on the interface between bond coat and the top coat. The oxidation of metallic substrate, bond coat and the presence of TGO scale at interface was examined by elemental mapping of YSZ coat after exposure of IR heating for $30 \mathrm{~s}$ as shown in figure 12. The elemental mapping for $\mathrm{Al}$ indicates a partial oxidation of $\mathrm{Al}$ in the bond coat, which was likely owing to reaction of atmospheric oxygen with $\mathrm{Al}$ during deposition. However, distribution of the other elements; such as Ni, $\mathrm{Cr}$ and $\mathrm{Y}$ as shown in figure 12 was uniform throughout the bond coat and did not show any oxidation. Figure 12 also reveals no evidence of further growth of TGO due to exposure to heat for small duration of IR heating. It is also clear from figure 12 that other elements of bond coat and top coat remain unaffected. The base alloy also remained unaffected by oxidation during coating deposition as well as after rapid exposure to high temperature for $30 \mathrm{~s}$.

\section{Conclusions}

TBCs of YSZ with different thicknesses and prior NiCrAlY bond coat were deposited on niobium alloy (C-103) substrates using the air plasma-spraying technique. Based on the results, the following conclusions are drawn:

i. The temperature difference between the back-wall surfaces (the opposite side of the IR heating) of the bare alloy and that of the coated alloy was found to be $\sim 75$ and $\sim 200^{\circ} \mathrm{C}$ for 300 and $600 \mu \mathrm{m}$ thick YSZ coating, respectively.

ii. The TBC provided excellent oxidation resistance to the substrate under rapid heating conditions and at $\sim 1250^{\circ} \mathrm{C}$ with minimal surface damage. The coating

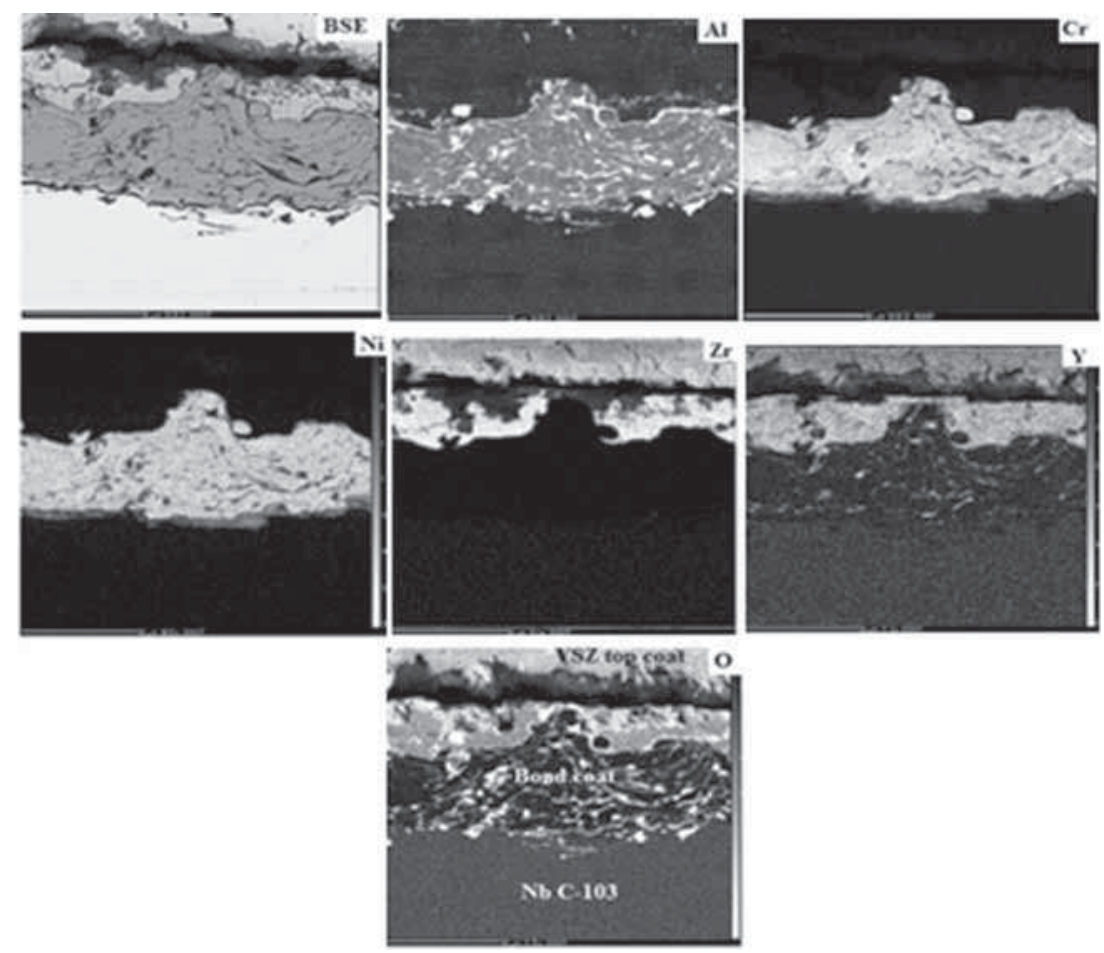

Figure 12. Elemental distribution of 300- $\mu$ m-thick YSZ coating on Nb alloy C-103 exposed to $1250^{\circ} \mathrm{C}$ for $30 \mathrm{~s}$. 
was found to be stable and intact after the heat treatment. Further, thicker YSZ coating along with the bond coat was found to provide better mechanical interlocking with the substrate, higher stress relaxation after heat treatment and better thermal insulation in terms of temperature drop across thickness.

iii. A significant surface stress and strain relaxation was observed on the coatings after IR heating by the generation of vertical cracks. Hardness of the coating surface increased after IR heating. Partial oxidation of aluminium present in bond coat was observed.

\section{Acknowledgement}

We would like to thank Defence Research and Development Organization for providing funding and facilities for carrying out the work.

\section{References}

[1] Ruckle D L 1980 Thin Solid Films 73455

[2] Rhys-Jones T N and Toriz F C 1989 High Temp. Technol. 773

[3] Dong Z L, Khor K A and Gu Y W 1999 Surf. Coat. Technol. 114181

[4] Khor K A and Yang J 1997 Surf. Coat. Technol. 96313

[5] Ravichandran K S, An K, Dutton R E and Semiatin S L 1999 J. Am. Ceram. Soc. 82673

[6] Scardi P, Leoni M and Bertamini L 1995 Surf. Coat. Technol. 76-77 106

[7] Ali M Y, Nusier S Q and Nawaz G M 2001 Int. J. Solids Struct. 383329
[8] Saremi M, Afrasiabi A and Kobayashi A 2008 Surf. Coat. Technol. 2023233

[9] Zhang C, Zhou C, Gong S, Li H and Xu H 2006 Surf. Coat. Technol. 201446

[10] Gurrappa I 2003 J. Mater. Sci. Technol. 19178

[11] Knight R, Smith R W, Zhangxiong D, Kime-H, Sahoo P and Bucci D Proceeding of 15th international thermal spray conference, May 1998 (NIC France) Vol II p 1549

[12] Mumm D R and Evans A G 2001 Durable Surf. 197199

[13] Vassen R, Kerkhof G and Stover D 2001 Mater. Sci. Eng. A Struct. Mater: Prop. Microstruct. Process. 303199

[14] Gurrappa I and Rao A S 2006 Surf. Coat. Technol. 2013016

[15] Song Y-S, Lee I-G, Lee D Y, Kim D-J and Kim S 2002 Mater. Sci. Eng. A 332129

[16] Khor K A and Gu Y W 2000 Mater. Sci. Eng. A 27764

[17] Gu Y M, Khor K A, Fu Y Q and Wang Y 1997 Surf. Coat. Technol. 96305

[18] Keyvani A, Saremi M, Heydazadehsohi M and Valefi Z 2012 J. Alloys Compd. 541488

[19] Novak M D and Levi C G 2007 Proceedings of ASME international mechanical engineering congress and exposition IMECE 2007, November 11-15, 2007 (Seattle, Washington, USA)

[20] Alam Z, Rao A S and Das D K 2010 Oxid. Met. 73513

[21] Shields Jr J A 1999 Surface engineering, ASM handbook, (revised by J A Shields) Vol 5 p 856

[22] Panwar S S, Prasad K, Patro T U and Balasubramanian K 2014 Mater. Sci. Eng. A 620286

[23] Cverna F (Tech editor), Thermal properties of metals, ASM Material Data Series (ASM: Material Park, Ohio) p 514

[24] Perrin N, Burlet H, Boussuge M and Desplanches G 1993 Surf. Coat. Technol. 56151 